Louisiana State University

LSU Digital Commons

$1-1-2000$

\title{
Ligand dissociation accelerated by spin state change: Locating the minimum energy crossing point for phosphine exchange in $\mathrm{CpMoCl}_{2}\left(\mathrm{PR}_{3}\right)_{2}$ complexes
}

\author{
Kevin M. Smith \\ Universite de Bourgogne \\ Rinaldo Poli \\ Universite de Bourgogne \\ Jeremy N. Harvey \\ University of Bristol
}

Follow this and additional works at: https://digitalcommons.Isu.edu/chemistry_pubs

\section{Recommended Citation}

Smith, K., Poli, R., \& Harvey, J. (2000). Ligand dissociation accelerated by spin state change: Locating the minimum energy crossing point for phosphine exchange in $\mathrm{CpMoCl}_{2}\left(\mathrm{PR}_{3}\right)_{2}$ complexes. New Journal of Chemistry, 24 (2), 77-80. https://doi.org/10.1039/a909646i

This Article is brought to you for free and open access by the Department of Chemistry at LSU Digital Commons. It has been accepted for inclusion in Faculty Publications by an authorized administrator of LSU Digital Commons. For more information, please contact ir@lsu.edu. 


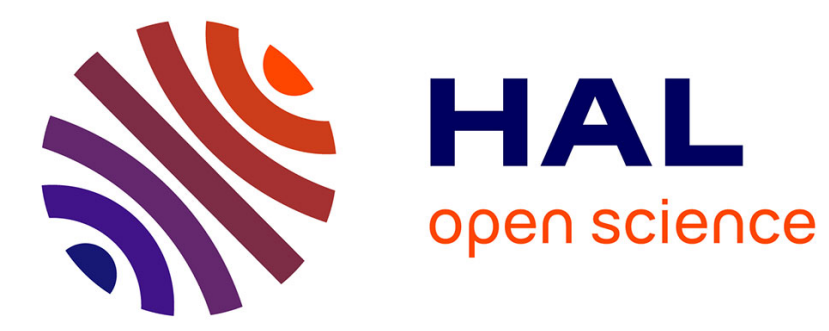

\section{Ligand dissociation accelerated by spin state change: locating the minimum energy crossing point for phosphine exchange in $\mathrm{CpMoCl2(PR3)2} \mathrm{complexes}$}

Kevin Smith, Rinaldo Poli, Jeremy Harvey

\section{- To cite this version:}

Kevin Smith, Rinaldo Poli, Jeremy Harvey. Ligand dissociation accelerated by spin state change: locating the minimum energy crossing point for phosphine exchange in $\mathrm{CpMoCl2(PR3)2} \mathrm{complexes.}$ New Journal of Chemistry, Royal Society of Chemistry, 2000, 24 (2), pp.77-80. 10.1039/A909646I . hal-03296191

\section{HAL Id: hal-03296191 \\ https://hal.archives-ouvertes.fr/hal-03296191}

Submitted on 28 Jul 2021

HAL is a multi-disciplinary open access archive for the deposit and dissemination of scientific research documents, whether they are published or not. The documents may come from teaching and research institutions in France or abroad, or from public or private research centers.
L'archive ouverte pluridisciplinaire HAL, est destinée au dépôt et à la diffusion de documents scientifiques de niveau recherche, publiés ou non, émanant des établissements d'enseignement et de recherche français ou étrangers, des laboratoires publics ou privés. 


\section{Ligand dissociation accelerated by spin state change: locating the minimum energy crossing point for phosphine exchange in $\mathrm{CpMoCl}_{2}\left(\mathrm{PR}_{3}\right)_{2}$ complexes.}

Kevin M. Smith, ${ }^{a}$ Rinaldo Poli*a and Jeremy N. Harvey*b

${ }^{a}$ Laboratoire de Synthèse et d'Electrosynthèse Organometallique, Faculté des Sciences "Gabriel", Université de Bourgogne, 6 Boulevard Gabriel, 21100 Dijon, France

${ }^{\mathrm{b}}$ School of Chemistry, University of Bristol, Cantock's Close, Bristol BS8 1TS, U.K. 
Summary: The minimum energy crossing point between the doublet and quartet potential energy surfaces of $\mathrm{CpMoCl}_{2}\left(\mathrm{PH}_{3}\right)_{2}$ is calculated to lie $4.8 \mathrm{kcal} \mathrm{mol}^{-1}$ lower in energy than the doublet dissociative intermediate $\mathrm{CpMoCl}_{2}\left(\mathrm{PH}_{3}\right)$. Implications for the influence of spin state changes on the rates of organometallic reactions are discussed.

The reactivity consequences of spin state changes in solution phase organometallic chemistry are not yet fully understood. ${ }^{1}$ Although it has been proposed that having to hop from the potential energy surface (PES) of one spin state to another might slow reactions down, several kinetic studies of ligand addition processes have found no such "spin flip barrier". ${ }^{2-4}$ The influence of spin state changes on the reactivity of transition metal ions in the gas phase, however, is fairly well established, ${ }^{5-}$ ${ }^{7}$ and these reactions provide useful models for condensed-phase processes. For example, studies of the reactions of gas phase metal oxide ions, such as that between $\mathrm{FeO}^{+}$and $\mathrm{CH}_{4}$, have recently led to new insights into the chemistry of cytochrome P-450 and of other metal-oxo species relevant to biochemistry and organic synthesis. ${ }^{8-14}$

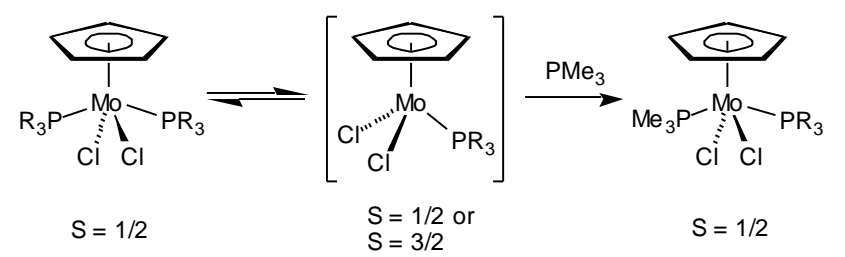

Several years ago, we reported that dissociative phosphine exchange reactions in spin doublet $\mathrm{CpMoCl}_{2}\left(\mathrm{PR}_{3}\right)_{2}$ complexes were unexpectedly fast (equation 1), and proposed that this acceleration was due to a facile spin-forbidden dissociation to a quartet $\mathrm{CpMoCl}_{2}\left(\mathrm{PR}_{3}\right)$ intermediate, occurring with a barrier lower than that for the pathway involving spin-allowed dissociation to the corresponding doublet. ${ }^{15}$ Recent advances in computational techniques, particularly density functional theory (DFT), ${ }^{16}$ have made it possible to assess the relative energies of unsaturated organometallic species in different spin states. Calculations on $\mathrm{CpMoCl}_{2}\left(\mathrm{PH}_{3}\right)_{\mathrm{n}}(\mathrm{n}=1,2)$ models confirmed that the proposed pathway would be thermodynamically favorable, with the $\mathrm{CpMoCl}_{2}\left(\mathrm{PH}_{3}\right)$ intermediate predicted to have a quartet ground state. ${ }^{17}$ Computational support for the all-important kinetic feasibility of the proposed mechanism was less forthcoming. Evaluation of rates of non-adiabatic reactions ${ }^{18}$ with spin state changes requires (a) an unambiguous determination of the 
energy at the minimum energy crossing point (MECP) between the relevant PESs, and (b) calculation of the strength of the spin-orbit-induced coupling between the two PESs at that point. In this Letter, we have calculated both points (a) and (b) for the $\mathrm{CpMoCl}_{2}\left(\mathrm{PH}_{3}\right)_{2}$ system. The MECP is found to lie considerably lower in energy than the spin doublet dissociative intermediate, and there is substantial spin-orbit coupling at that point, in full support of the mechanistic hypothesis. For point (a), we have compared two approaches for locating the MECP: the partial optimization method, which has been frequently used in studies of transition metal chemistry; and the explicit full-dimensional optimization of the MECP, which had not until now been performed for such large, realistic polyatomic models such as that studied here. We believe that this latter method will prove to be more broadly useful for the theoretical investigation of spin state effects in transition metal chemistry in solution. $8,9,19-21$

In the first place, we have studied the crossing between the doublet and quartet PESs of the $\mathrm{CpMoCl}_{2}\left(\mathrm{PH}_{3}\right)_{2}$ system using the partial optimization method. This approach has already been frequently used to estimate the position of the MECP in various complex models of solution phase organometallic reactions. $^{22-26}$ It involves multiple geometry optimizations on both PESs whilst holding constant one carefully selected internal geometry parameter, until a value for the parameter is obtained at which both spin states have the same energy. The parameter chosen is usually a bond length, or an angle between two bonds, which has markedly different values at the minima corresponding to the two spin states. Because of the multiple partial geometry optimizations required, the method can be rather computationally expensive, but of more concern is the fact that it only provides an estimate of the lower energy limit to the MECP because all the other degrees of freedom are optimized separately on the two surfaces. Therefore, the "Crossing Point" located using this technique is in fact two different points, which, depending on which unique parameter is chosen, and on the features of the two PESs, may or may not be very similar to each other and to the real MECP. A measure of how different the two points are can be obtained by computing single point energies on each PES at the partially optimized geometry of the other one. These energies can also be used as very rough upper energy limits for the MECP. 


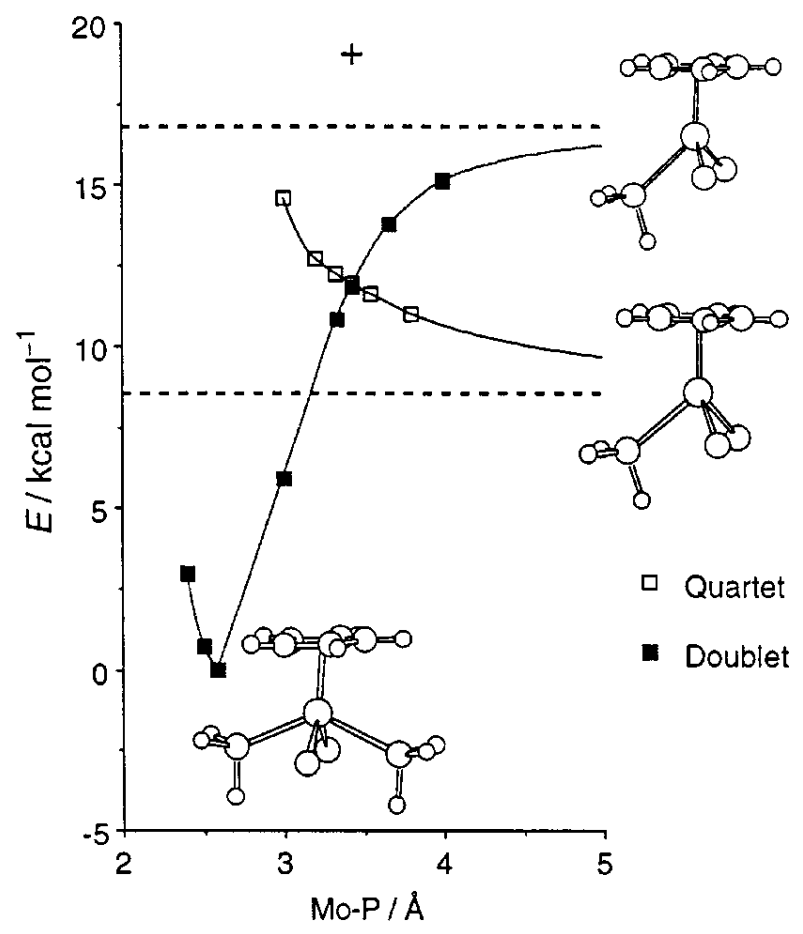

Figure 1. Energies of partially optimized doublet and quartet $\mathrm{CpMoCl}_{2}\left(\mathrm{PH}_{3}\right)_{2}$ relative to the overall doublet minimum, at various fixed Mo-P distances, including dissociated $\mathrm{CpMoCl}_{2}\left(\mathrm{PH}_{3}\right)$ (dashed lines) and estimated upper limit of crossing point energy $(+)$.

The results of our DFT computations on the dissociation of $\mathrm{PH}_{3}$ from $\mathrm{CpMoCl}_{2}\left(\mathrm{PH}_{3}\right)_{2}$ using this procedure are illustrated in Figure 1 and Table 1 . As noted previously, ${ }^{17}$ the dissociated 15electron $\mathrm{CpMoCl}_{2}\left(\mathrm{PH}_{3}\right)$ species has a quartet ground state, calculated here to lie $8.4 \mathrm{kcal} \mathrm{mol}^{-1}$ below the doublet. The coordinate we have chosen to vary is the Mo-P distance, along which the interaction of doublet $\mathrm{CpMoCl}_{2}\left(\mathrm{PH}_{3}\right)$ with the incoming phosphine ligand is purely attractive, whereas the corresponding quartet PES is purely repulsive. The two curves cross, near the point with a fixed Mo-P distance of $3.43 \AA$. At that distance, their relative energies (defined with respect to the $\mathrm{CpMoCl}_{2}\left(\mathrm{PH}_{3}\right)_{2}$ doublet minimum) are both within $0.1 \mathrm{kcal} \mathrm{mol}^{-1}$ of $11.9 \mathrm{kcal} \mathrm{mol}^{-1}$. Single point computations for each spin state at the partially optimized geometry of the other spin state give higher energies, of 18.9 and $20.2 \mathrm{kcal} \mathrm{mol}^{-1}$, respectively, for the doublet and the quartet. This reflects the differences between the partially optimized geometries on the two PESs (Figure 1), which are significant if not enormous. ${ }^{27}$ The estimated lower and upper limits to the MECP's energy obtained in this way can be seen (Fig. 1) to lie, respectively, well below and just above the doublet dissociation asymptote of $16.9 \mathrm{kcal} \mathrm{mol}^{-1}$. Although the lower limit is the more reliable of the two, there does 
remain a certain ambiguity as to the position of the MECP, and therefore, as to whether or not the pathway for spin-forbidden dissociation to the quartet will be kinetically favored over the spinallowed doublet route.

Table 1. Mo-P bond lengths $(\AA)$ and relative energies (in $\mathrm{kcal} \mathrm{mol}^{-1}$, relative to optimized doublet $\left.\mathrm{CpMoCl}_{2}\left(\mathrm{PH}_{3}\right)_{2}\right)$ of spin doublet and quartet $\mathrm{CpMoCl}_{2}\left(\mathrm{PH}_{3}\right)_{2}$ complexes.

\begin{tabular}{l|ccc} 
Complex & Mo-P & Doublet & Quartet \\
\hline $\mathrm{CpMoCl}_{2}\left(\mathrm{PH}_{3}\right)_{2}$ & 2.580 & 0.0 & - \\
$\mathrm{CpMoCl}_{2}\left(\mathrm{PH}_{3}\right)+\mathrm{PH}_{3}$ & - & +16.9 & +8.5 \\
partial optimization & 3.430 & +11.9 & +11.8 \\
estimated upper limits & 3.430 & +18.9 & +20.2 \\
MECP & 3.201 & +12.1 & +12.1
\end{tabular}

The importance of locating MECPs explicitly when trying to understand spin-forbidden reaction mechanisms is well recognized, and several groups have done so in the study of mediumsized organic and main-group inorganic systems. Recent examples include the interconversion of singlet and triplet phenyl cation, ${ }^{28,29}$ the unimolecular dissociations of triplet methoxy cation ${ }^{30}$ and of ethylenedione, ${ }^{31}$ and the two combustion reactions, $\mathrm{HC}+\mathrm{N}_{2}{ }^{32}$ and $\mathrm{O}+\mathrm{C}_{2} \mathrm{H}_{2} \cdot{ }^{33}$ Some applications to small transition-metal containing systems have also been reported, such as the gas-phase dehydrogenation of methane by the Scandium cation. ${ }^{34}$ However, many of the methods available for finding MECPs ${ }^{35,36}$ are based on the use of complete active space self-consistent field (CASSCF) computations, whose expense generally scales very badly with system size. Although many useful results can be obtained with carefully executed CASSCF computations on transition metal systems, ${ }^{37}$ this expense factor does in part explain why no MECP for a reaction of a large organometallic compound has yet been optimized. However, except when the wavefunction of one or both of the spin-states is intrinsically multi-referential in nature, which is not the case here, there is no fundamental reason why CASSCF-based computations are needed to locate MECPs. Instead, any $a b$ initio method, provided it describes both states in a sufficiently accurate way, can be used for this 
purpose. ${ }^{26,38}$ Our approach, ${ }^{26}$ which is a simple modification of two previously described ones, ${ }^{36,38}$ relies on combining the separately computed energies and gradients on the two PESs so as to produce an effective gradient which is then followed downhill towards the MECP. Its compatibility with DFT computations, the method of choice at the present time for computations on large transition metal systems, ${ }^{16}$ makes it ideal for the present work.

We have accordingly optimized the geometry (Figure 2) of the MECP between the doublet and quartet PESs of $\mathrm{CpMoCl}_{2}\left(\mathrm{PH}_{3}\right)_{2}$. The structure obtained is similar to those derived using the partial optimization method. Interestingly, the main difference is in the "special" Mo-P distance, which is over $0.2 \AA$ shorter in the fully optimized structure. The relative energy at the MECP is of $12.1 \mathrm{kcal} \mathrm{mol}^{-1}$, i.e. $4.8 \mathrm{kcal} \mathrm{mol}^{-1}$ lower than the doublet dissociation asymptote. We have also used computations to estimate the root-mean square (rms) doublet-quartet spin-orbit coupling at the MECP, and find it to be on the order of $250 \mathrm{~cm}^{-1}$. This value is large enough to ensure facile surfacehopping at the MECP. ${ }^{39}$ Combining these results on the energy of the MECP and the spin-orbit coupling provides full support for the mechanistic hypothesis, whereby dissociation of doublet $\mathrm{CpMoCl}_{2}\left(\mathrm{PH}_{3}\right)_{2}$ proceeds through the quartet intermediate, $\mathrm{CpMoCl}_{2}\left(\mathrm{PH}_{3}\right)$. Thus, far from being a hindrance, the spin state change actually facilitates ligand dissociation by lowering the activation enthalpy compared to an alternative reaction pathway that remains confined to the doublet PES. ${ }^{15}$

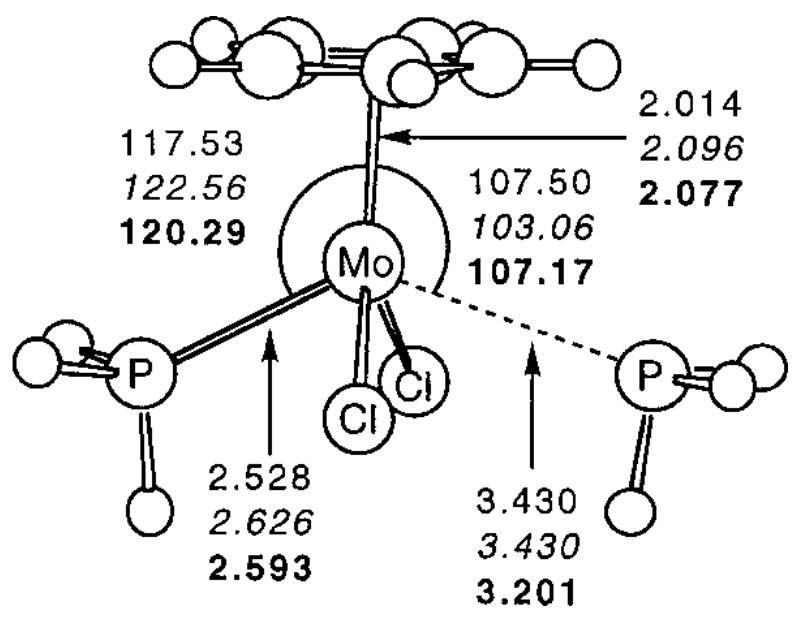

Figure 2. Optimized geometry of MECP between doublet and quartet $\mathrm{CpMoCl}_{2}\left(\mathrm{PH}_{3}\right)_{2}$.

Selected bond lengths and angles for partially optimized doublet (plain text), partially optimized quartet (italics), and MECP (bold). 
To compare the two methods for characterizing MECPs, one can see that the energy of the fully optimized structure is rather close to that of the crossing point of the partial optimization curves. Also, the geometries are reasonably close, with the exception of the Mo-P distance, where there is a quite significant difference. The overall good agreement obtained is probably due to the nature of the reaction: for the phosphine exchange process, the choice of the Mo-P bond as a "special" coordinate for the partial optimization process is relatively straightforward, and the differences in the optimized values of the other parameters on the two surfaces, whilst significant, are not major. The fact that the explicit MECP localization does not require a "special" coordinate, and can be started from an arbitrarily chosen geometry, ${ }^{28,36,38}$ is potentially valuable for cases where identifying such a parameter is less obvious. Before explicitly optimizing the MECP, it was not immediately apparent that the differences between the optimized values for the other degrees of freedom on the two PESs would not exert a more severe influence. While the only criterion available for judging the quality of the partial optimization result, the single-points upper limit calculations, provide little help, the explicit MECP localization is unambiguous. It is also a matter of interest to note that fully optimizing the MECP is the less computationally demanding of the two approaches. Overall, therefore, apart from availability issues, there appears to be no reason to prefer partial optimization in studies of crossings of PESs of different spin.

In contrast to gas phase studies of transition metal ions, much work remains to be done to investigate the effect of spin state changes on reactivity in solution phase organometallic chemistry. Recently, spin state effects in solution have been addressed in the reactions of metal oxo compounds, and in $\mathrm{C}-\mathrm{H}$ and $\mathrm{Si}-\mathrm{H}$ activation by unsaturated $\mathrm{CpM}(\mathrm{CO})_{n}$ species. In these cases, different spin states exhibit distinct reactivity patterns, and the factors which influence the spin crossover process play a dramatic role in dictating the observed reactivity. It is hoped that the computational determination of MECPs in transition metal systems, using the explicit technique shown to be possible and preferable in this Letter, will prove useful in the identification and examination of further examples of this phenomenon. More generally, we believe this will contribute to an enhanced awareness and understanding of the effects of spin state changes in organometallic reactions.

\section{Computational Details}


The $a b$ initio computations descibed in this Letter were mostly performed with Gaussian $94,{ }^{40}$ using the B3LYP hybrid density functional, together with the standard LanL2DZ basis sets on all atoms, and the associated effective core potentials on the Mo, P and $\mathrm{Cl}$ centers. Unrestricted "wavefunctions" were used throughout, with the expectation value of $S^{2}$ being very close to its ideal value in all cases. $\mathrm{C}_{\mathrm{S}}$ symmetry was assumed for all structures. For the calculation of the spin-orbit coupling, the semiempirical effective nuclear charge-one electron operator approach ${ }^{41}$ was applied, using the GamessUSA program. ${ }^{42}$ Full CI wavefunctions in the space of the Mo $4 \mathrm{~d}$ orbitals were used to describe the doublet and quartet. Due to computational restrictions, these were expanded using ROHF orbitals optimized for one of the two states, with a standard double-zeta all-electron basis set on all the lighter atoms, together with the standard SBK relativistic ECP and basis set on Mo. The effective charges used were those of ref. 41(a), except for Mo, where a value of 200 was optimized to fit the experimental splitting of $\mathrm{Mo}^{3+}\left({ }^{4} \mathrm{~F}\right)$. The low quality of the wavefunctions used is shown by the different values obtained using the quartet ( $\left.\mathrm{rms} \mathrm{SOC} 314 \mathrm{~cm}^{-1}\right)$ and doublet $\left(213 \mathrm{~cm}^{-1}\right)$ orbitals in the calculations. Based on experience with other systems, ${ }^{26-31}$ however, we believe that as an estimate, our proposed value of $250 \mathrm{~cm}^{-1}$ should not be too far wrong.

Acknowledgement. R. P. thanks the Région Bourgogne for supporting this research, J. N. H. thanks Prof. G. G. Balint-Kurti for computational resources, and Mike Schmidt for providing the Gamess-USA program, and K. M. S. thanks the European Commission for a TMR Marie Curie Postdoctoral Fellowship.

1 R. Poli, Chem. Rev., 1996, 96, 2135-2204.

2 A. H. Janowicz, H. E. Bryndza and R. G. Bergman, J. Am. Chem. Soc., 1981, 103, 1516-1518.

3 A. A. Bengali, R. G. Bergman and C. B. Moore, J. Am. Chem. Soc., 1995, 117, 3879-3880.

4 J. L. Detrich, O. M. Reinaud, A. L. Rheingold and K. H. Theopold, J. Am. Chem. Soc., 1995, 117, 11745-11748.

5 J. C. Weisshaar, Acc. Chem. Res., 1993, 26, 213-219.

6 P. B. Armentrout, Acc. Chem. Res., 1995, 28, 430-436. 
7 P. A. M. van Koppen, M. T. Bowers, C. L. Haynes and P. B. Armentrout, J. Am. Chem. Soc., 1998, 120, 5704-5712.

8 S. Shaik, M. Filatov, D. Schröder and H. Schwarz, Chem. Eur. J., 1998, 4, 193-199.

9 D. A. Plattner, Angew. Chem. Int. Ed., 1999, 38, 82-86.

10 P. H. Toy, M. Newcomb and P. F. Hollenberg, J. Am. Chem. Soc., 1998, 120, 7719-7729.

11 P. E. M. Siegbahn and R. H. Crabtree, J. Am. Chem. Soc., 1999, 121, 117-127.

12 M. Filatov, N. Harris and S. Shaik, J. Chem. Soc., Perkin Trans. 2, 1999, 399-410.

13 N. Jin and J. T. Groves, J. Am. Chem. Soc., 1999, 121, 2923-2924.

14 C. Linde, B. ₹kermark, P.-O. Norrby and M. Svensson, J. Am. Chem. Soc., 1999, 121, $5083-5084$.

15 A. A. Cole, J. C. Fettinger, D. W. Keogh and R. Poli, Inorg. Chim. Acta, 1995, 240, 355-366.

16 P. E. M. Siegbahn, Adv. Chem. Phys., 1996, 93, 333-387.

17 I. Cacelli, D. W. Keogh, R. Poli and A. Rizzo, J. Phys. Chem. A, 1997, 101, 9801-9812.

18 For an overview of non-adiabatic chemistry, see D. R. Yarkony, J. Phys. Chem., 1996, 100, $18612-18628$.

19 P. E. M. Siegbahn, J. Am. Chem. Soc., 1996, 118, 1487-1496.

20 H. Yang, M. C. Asplund, K. T. Kotz, M. J. Wilkens, H. Frei and C. B. Harris, J. Am. Chem. Soc., 1998, 120, 10154-10165.

21 J. N. Harvey, in Computational Organometallic Chemistry, T. C. Cundari, Ed., Marcel Dekker, in press.

22 D. W. Keogh and R. Poli, J. Am. Chem. Soc., 1997, 119, 2516-2523.

23 J. C. Green and C. N. Jardine, J. Chem. Soc., Dalton Trans., 1998, 1057-1061.

24 S. A. Decker and M. Klobukowski, J. Am. Chem. Soc., 1998, 120, 9342-9355.*

25 E. Collange, D. Duret and R. Poli, J. Chem. Soc., Dalton Trans., 1999, 875-879.

26 K. M. Smith, R. Poli and P. Legzdins, Chem. Eur. J., 1999, 5, 1598-1608.

27 As previously noted, quartet $\mathrm{CpMoCl}_{2}\left(\mathrm{PH}_{3}\right)$ posseses a normal three-legged piano stool

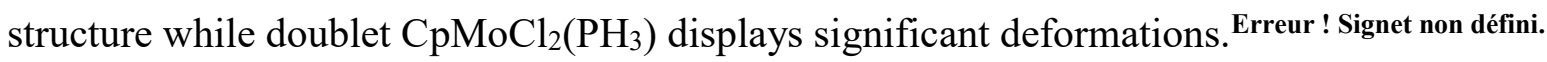
The distortions in the 15-electron doublet species are analogous to those in $\mathrm{d}^{4} \mathrm{CpML}_{3}$ and $\mathrm{d}^{6}$ $\mathrm{CpML}_{2}$ 16-electron singlet complexes: see (a) P. Kubácek, R. Hoffmann and Z. Havlas, 
Organometallics, 1982, 1, 180-188. (b) T. J. Johnson, K. Folting, W. E. Streib, J. D. Martin, J. C. Huffman, S. A. Jackson, O. Eisenstein and K. G. Caulton, Inorg. Chem., 1995, 488-499. (c)

T. R. Ward, O. Schafer, C. Daul and P. Hofmann, Organometallics, 1997, 16, 3207-3215. (d)

K. Costuas and J.-Y. Saillard, Organometallics, 1999, 18, 2505-2512.

28 J. N. Harvey, M. Aschi, H. Schwarz and W. Koch, Theor. Chem. Acc., 1998, 99, 95-99.

29 M. Aschi and J. N. Harvey, J. Chem. Soc., Perkin Trans. 2, 1999, 1059-1062.

30 M. Aschi, J. N. Harvey, C. A. Schalley, D. Schröder and H. Schwarz, Chem. Commun., 1998, $531-532$.

31 D. Schröder, C. Heinemann, H. Schwarz, J. N. Harvey, S. Dua, S. J. Blanksby and J. H. Bowie, Chem. Eur. J., 1998, 4, 2550-2557.

32 K. Morokuma, Q. Cui and Z. Liu, Faraday Discuss., 1998, 110, 71-89.

33 D. R. Yarkony, J. Phys. Chem. A, 1998, 102, 5305-5311.

34 D. G. Musaev and K. Morokuma, J. Phys. Chem., 1996, 100, 11600-11609.

35 D. R. Yarkony, J. Phys. Chem., 1993, 97, 4407-4412.

36 M. J. Bearpark, M. A. Robb and H. B. Schlegel, Chem. Phys. Lett., 1994, 223, 269-274.

37 B. O. Roos, Acc. Chem. Res., 1999, 32, 137-144.

38 N. Koga and K. Morokuma, Chem. Phys. Lett., 1985, 119, 371-374.

39 The value is however not so large that the original doublet and quartet PESs should be considered to be completely inadequate zero-th order descriptions of the system. This may of course be different in other cases, especially those involving third row (5d) transition metals.

40 M. J. Frisch, G. W. Trucks, H. B. Schlegel, P. M. W. Gill, B. G. Johnson, M. A. Robb, J. R. Cheeseman, T. Keith, G. A. Petersson, J. A. Montgomery, K. Raghavachari, M. A. Al-Laham, V. G. Zakrzewski, J. V. Ortiz, J. B. Foresman, J. Cioslowski, B. B. Stefanov, A. Nanayakkara, M. Challacombe, C. Y. Peng, P. Y. Ayala, W. Chen, M. W. Wong, J. L. Andres, E. S. Replogle, R. Gomperts, R. L. Martin, D. J. Fox, J. S. Binkley, D. J. Defrees, J. Baker, J. P. Stewart, M. Head-Gordon, C. Gonzalez and J. A. Pople, Gaussian 94 (Revision E.1); Gaussian Inc.: Pittsburgh, PA, 1995.

41 (a) S. Koseki, M. W. Schmidt and M. S. Gordon, J. Phys. Chem., 1992, 96, 10768-10772; (b)

S. Koseki, M. S. Gordon and M. W. Schmidt, J. Phys. Chem., 1995, 99, 12764-12772. 
42 Gamess-USA: M. W. Schmidt, K. K. Baldridge, J. A. Boatz, S. T. Elbert, M. S. Gordon, J. H. Jensen, S. Koseki, N. Matsunaga, K. A. Nguyen, S. J. Su and T. L. Windus; together with M. Dupuis and J. A. Montogomery, J. Comput. Chem., 1993, 14, 1347-1363. 